\title{
Studi Kualitatif: Sumber Self-Efficacy Mobilisasi Pasien selama Perawatan di Rumah Sakit
}

\author{
Lina Erlina \\ Jurusan Keperawatan Bandung, Politeknik Kesehatan Kemenkes Bandung, Indonesia \\ Email: linahiar@yahoo.co.id
}

\begin{abstract}
Qualitative Study: Source of Self-Efficacy of Patient for Mobilization during Hospitalization. High self-efficacy increases a person's ability to achieve certain targets beyond their actual abilities. The role of self-efficacy on the mobilization ability patient's during hospitalization has been proven. However, the source of self-efficacy of the patient for mobilization is not yet known. This study aimed to know what sources of self-efficacy of the patient for mobilization during hospitalization. This study used a qualitative study in which the data collected through in-depth interviews with 10 patients in the internal medicine room. Eight themes were obtained: 1) Habits of mobilization before illness, 2) Effects that patients feel after mobilizing, 3) Availability of mobilization facilities, 4) The success of other patients mobilizes, 5) verbal expressions directly from other people, 6) Self-statement, 7) Patient's physical condition, 8) Patient's psychological condition. Obtained eight themes of the source self-efficacy of the patient for mobilization during hospitalization, but it is not yet known which source is the most important. Further research is needed to find out the role of mobilization self-efficacy sources towards increasing patient mobilization capabilities.
\end{abstract}

Keywords: Mobilization, Patients during hospitalization, Source of self-efficacy

\begin{abstract}
Abstrak: Studi Kualitatif: Sumber Self-Efficacy Mobilisasi Pasien selama Perawatan di Rumah Sakit. Self-efficacy yang tinggi meningkatkan kemampuan seseorang mencapai target tertentu melebihi kemampuan sebenarnya. Peran self-efficacy terhadap kemampuan mobilisasi pasien selama perawatan di Rumah Sakit (RS) telah terbukti, namun sumber self-efficacy mobilisasi pasien sampai saat ini belum diketahui. Tujuan penelitian adalah mengetahui apa sumber self-efficacy mobilisasi pasien selama perawatan. Metode penelitian studi kualitatif dengan pengumpulan data menggunakan wawancara mendalam pada 10 pasien yang dirawat di ruang penyakit dalam. Didapatkan 8 tema sumber self-efficacy mobilisasi yaitu 1) Kebiasaan pasien melakukan mobilisasi sebelum dirawat, 2) Efek yang dirasakan pasien setelah melakukan mobilisasi, 3) Ketersediaan fasilitas saat pasien melakukan mobilisasi, 4) Keberhasilan pasien lain melakukan mobilisasi selama perawatan, 5) Pernyataan langsung dari orang lain kepada pasien tentang kemampuan mobilisasinya, 6) Pernyataan dari diri sendiri, 7) Kondisi fisik yang dirasakan pasien saat ini, 8) Kondisi psikis yang dirasakan pasien saat ini. Didapatkan delapan tema sumber self-effficacy mobilisasi pasien selama perawatan di RS, namun belum diketahui sumber mana yang paling berperan. Diperlukan penelitian lanjutan untuk mengetahui peran sumber self-efficacy mobilisasi terhadap peningkatan kemampuan mobilisasi pasien.
\end{abstract}

Kata Kunci: Sumber self-efficacy, Mobilisasi, Pasien selama perawatan

\section{PENDAHULUAN}

Mobilisasi didefinisikan sebagai kemampuan untuk bergerak dari satu tempat ke tempat lain dengan bebas dan aman (Kleffelgaard, 2013; Perry \& Potter, 2006). Gangguan mobilisasi fisik didefinisikan North American Nursing Diagnosis Association (NANDA) sebagai immobilisasi (Kim et al dalam Perry \& Potter, 2006). Immobilisasi pada pasien selama perawatan di RS dapat terjadi karena perlakuan tirah baring sebagai salahs atu faktor penyebab hilangnya kemampuan mobilisasi pasien (Perry \& Potter, 2006).

Awal tahun 1960 sampai 1900 intervensi tirah baring dijadikan sebagai standar keperawatan dalam praktek keperawatan (Theresa \& Fox, 2007). Perubahan terjadi seiring adanya perdebatan didunia kedokteran tentang efek tirah baring. Awal tahun 1944 mulai dipublikasikan berbagai komplikasi akibat tirah baring. Intervensi tirah baring mulai di tentang 
sebagai intervensi "best practice"dan anjuran "long day in bed" berakhir pada tahun 1955 (Theresa \& Fox, 2007). Sejak itulah intervensi mobilisasi mulai direkomendasikan menjadi standar keperawatan pasien. Hal ini dapat dilihat pada Buku teks keperawatan pada awal tahun 1960-an (Fuerst \& Wolff, 1969) yang menjelaskan secara rinci tentang pentingnya ambulasi/mobilisasi baik pada pasien tirah baring maupun pasien rawat jalan.

Berbagai hasil penelitian menyimpulkan efek tirah baring mempengaruhi berbagai fungsi tubuh baik secara fisiologis maupun psikologis. Efek fisiologik meliputi melemahnya fungsi metabolik, kardiovaskuler, pulmonal, muskuloskeletal, hematologik, sistem imun, thermoregulasi, neuroendokrin dan organ lainnya (Sonne et al, 2010; Alibegovic et al, 2009; Smorawiński et al., 2001; Krasnoff \& Painter, 1999). Efek tirah baring secara psikologis dijelaskan (Perry \& Potter, 2006) diantaranya menyebabkan perubahan respon emosional yang umumnya ditandai dengan pasien mengalami depresi, perubahan perilaku, perubahan siklus tidur-bangun, dan gangguan koping. Hasil studi Ishizakietal terjadi pening katan tingkat depresi dan gejala neurotikpada individu setelah 20 hari tirah baring (Liu, Zhou, Chen, \& Tan, 2012).

Berbagai kondisi pasien menjadi kendala besar untuk melaksanakan mobilisasi sehingga tirah baring sampai saat ini masih banyak dilakukan pasien. Mahoney dalam King (2010) melakukan pengamatan pada 118 pasien yang dirawat di RS yang mampu berjalan, didapatkan hanya $9,4 \%$ yang melakukan kegiatan berjalan dengan didampingi perawat dan $72,9 \%$ tidak melakukan kegiatan berjalan. Penelitian pada lansia yang dirawat dirumah sakit dinyatakan Brown dalam Doherty-king et al (2012) bahwa 83\% dari waktu pasien dihabiskan dengan berbaring ditempat tidur.

Faktor-faktor yang berpengaruh terhadap mobilisasi sangat berperan dalam menentukan kemampuan pasien. Beberapa penelitian menyimpulkan hasil yang bervariasi tentang faktorfaktor yang mempengaruhi mobilisasi pasien sehingga pengkajian yang komprehensif terkait hal tersebut mutlak diperlukan. Faktor fisik maupun psikis berkontribusi terhadap kemampuan pasien. Self-efficacy merupakan faktor psikis yang paling menentukan sejauhmana kegiatan dapat dilakukan dan harus bagaimana cara melakukannya (Roberts, Dolansky, \& Weber, 2010).

Self-efficacy merupakan konstruk yang digunakan dalam social cognitive theory. Didefinisikan sebagai keyakinan seseorang tentang kemampuan dirinya untuk dapat menyelesaikan tugas tertentu (Bandura, 2006). Peran self-efficacy terhadap tindakan seseorang telah dibuktikan dalam berbagai penelitian diantaranya pengaruhnya terhadap keseimbangan, aktifitas sehari-hari, dan kepatuhan melakukan latihan (A. L. Harrison, 2004). Beberapa hasil penelitian lainnya juga terbukti bahwa self-efficacy memiliki dampak meningkatkan kemampuan seseorang (Oei \& Burrow, 2000; Hellström et al, 2003; Baldwin et al, 2006; Cramp dan Bray, 2009).

Bandura (1997) menyatakan secara umum terdapat empat sumber self-efficacy yaitu mastery experience, vicarious experience, verbal persuasion dan physiological and affective states. Lebih lanjut Bandura menjelaskan bahwa mastery experience merupakan sumber yang paling berperan diantara sumber lainnya. Namun sumber self-efficacy mobilisasi yang berperan terhadap kemampuan mobilisasi pasien selama perawatan di rumah sakit sampai saat ini masih belum banyak diketahui, meskipun self-efficacy telah terbukti secara konsisten berpengaruh terhadap perilaku seseorang. Identifikasi sumber self-efficacy mobilisasi serta faktor lainnya merupakan hal penting yang harus dilakukan perawat, sehingga perawat dapat menentukan intervensi keperawatan yang tepat untuk meningkatkan kemampuan mobilisasi pasien berdasarkan sumber self-efficacy yang mempengaruhinya, sehingga efek negatif imobilisasi dapat dihindari dan peningkatan kesehatan terjadi.

\section{METODE}

Penelitian merupakan studi kualitatif. Pengumpulan data menggunakan wawancara mendalam pada 10 pasien di Ruang Penyakit Dalam di RS Hasan Sadikin Bandung. Kriteria inklusi sampel ditetapkan sebagai berikut: kesadaran pasien compos mentis, memiliki kekuatan otot ekstremitas bawah dengan score minimal 4, memiliki kemampuan melakukan perubahan posisi: bangun dari tempat tidur dan duduk di samping tempat tidur dengan atau tanpa bantuan orang lain/alat bantu, memahami bahasa Indonesia, dan kooperatif. Pasien tidak diambil sebagai sampel penelitian dengan kriteria ekslusi sebagai berikut: Pasien terpasang $\mathrm{O}_{2}$ lebih dari 2 liter/menit, terpasang chest tube dan atau central line, pasien sedang mengalami demam.

Pengumpulan data menggunakan pedoman wawancara terbuka yang menggali tentang pengalaman pasien melakukan mobilisasi sebelum dan selama dirawat di RS, hambatan yang dirasakan, usaha yang dilakukan mengatasi 
hambatan, faktor-faktor yang memotivasi pasien melakukan mobilisasi. Kemudian Data dianalisis dengan metode colaizzi. Sehingga didapatkan tema-tema yang sesuai menggambarkan sumbersumber self-efficacy mobilisasi pasien selama masa perawatan.

Etical clearance telah didapatkan dari Komite Etik Penelitian RS hasan Sadikin Bandung. Semua sampel mendapatkan informasi terkait penelitian dan telah memahaminya sebelum menandatangi informed consent.

\section{HASIL}

Sampel penelitian adalah pasien yang sedang dirawat di ruang penyakit dalam. Berikut dijelaskan karakteristik sampel yaitu:Sampel berjenis kelamin perempuan $70 \%$, rentang usia 22-72 tahun, tingkat pendidikan minimal SMA $70 \%$, semua sampel memiliki score kekuatan otot 5, lama hari rawat 3-6 hari, dan alat kesehatan yang terpasang ditubuh pasien 1-3 macam alat. Lebih jelas dapat dilihat pada tabel 1 .

Tabel 1. Karakteristik Partisipan

\begin{tabular}{rrrllrrr}
\hline No & JK & Usia & Didik & Kerja & Otot & Lama & $\begin{array}{c}\text { Al } \\
\text { kes }\end{array}$ \\
\hline 1 & L & 49 & SMA & Kerja & 5 & 6 & 1 \\
\hline 2 & L & 25 & SMA & tidak & 5 & 6 & 1 \\
\hline 3 & P & 72 & SD & tidak & 5 & 5 & 2 \\
\hline 4 & P & 54 & SMA & kerja & 5 & 3 & 1 \\
\hline 5 & P & 22 & SMA & tidak & 5 & 3 & 1 \\
\hline 6 & P & 50 & SMA & kerja & 5 & 6 & 2 \\
\hline 7 & P & 31 & SMA & tidak & 5 & 3 & 1 \\
\hline 8 & P & 54 & SMP & tidak & 5 & 3 & 1 \\
\hline 9 & L & 46 & S1 & kerja & 5 & 4 & 3 \\
\hline 10 & P & 62 & SMP & tidak & 5 & 4 & 1 \\
\hline & & & & & & &
\end{tabular}

Penelitian menghasilkan 8 tema sumber self efficacy, yang diuraikan sebagai berikut:

\section{Kebiasaan pasien melakukan mobilisasi sebelum dirawat}

Hasil analisis verbatim didapatkan beberapa pengalaman pasien tentang kebiasaan melakukan mobilisasi baik saat sehat maupun saat sakit sebelum dirawat di RS. Kebiasaan mobilisasi saat pasien sehat dapat dilihat dari beberapa pernyataan berikut:

"saya biasa melakukan apapun sendiri..." (P1)

"dari dulu juga saya tidak suka merepotkan orang lain..." (P2)

" lebih enak melakukan sendiri, lebih leluasa..” (P2)

"malu kalau tergantung orang lain...” (P4)

"risih kalau dibantu terus..." (P7) "ada yang membantu saya kalau di rumah... tidak boleh cape oleh anak saya” (P6)

Kebiasaaan mobilisasi saat sakit didapatkan beberapa pernyataan yang menunjukkan pasien biasa melakukan mobilisasi mandiri. Pernyataan dapat dilihat berikut ini:

"kalau sakit saya tidak enak hanya tiduran saja, harus tetap aktifitas seperti biasa..." (Pl)

"saya berupaya sendiri, kecuali kalau saya sudah tidak kuat lagi baru saya minta tolong ngambil ini, ngambil itu..." (P7)

Berbeda dengan pasien lain yang menunjukkan bahwa saat sakit lebih suka dibantu untuk mobilisasi. Pernyataan tersebut dapat dilihat berikut ini:

"kalau sakit lebih enak tiduran saja.." (P3)

"Kalau sakit saya lebih suka dibantu, supaya lebih enak tidak capek..." (P9)

\section{Efek yang dirasakan pasien saat melakukan mobilisasi}

Berbagai efek dirasakan pasien setelah melakukan mobilisasi selama perawatan di RS. Hal ini dapat mempengaruhi keyakinan pasien terhadap kemampuannya melakukan mobilisasi. Beberapa pernyataan tentang efek yang dirasakan pasien terbagi menjadi dua yaitu efek fisik dan efek psikis. Pernyataan yang menggambarkan efek fisik yaitu:

"jadi capek, tambah nyeri.. "(P3)

"ke badan jadi lemes, pusing..." (P6)

"kalo turun dari tempat tidur jadi lemes.." (P9)

"jadi seger kalau jalan-jalan...” (P10)

"enak tidak pegal...tidur terus badan jadi pegal.."(P10)

Pernyataan pasien yang menggambarkan efek psikis yaitu:

"enak tidak sumpek, bosan tiduran aja..." (P2)

"sebenarnya malas, saya lebih suka tiduran.." (P3)

"jadi lebih semangat kalau habis jalanjalan..." (P5)

\section{Ketersediaan fasilitas saat melakukan mobilisasi}

Ketersediaan fasilitas sangat menunjang tumbuhnya keyakinan pasien melakukan mobilisasi. Hasil analisis verbatim didapatkan ada dua katagori fasilitas yang dibutuhkan pasien yaitu ketersediaan fasilitas lingkungan dan fasilitas alat yang dibutuhkan. Kebutuhan 
tersedianya fasilitas lingkungan untuk mobilisasi selama perawatan dapat dilihat dari pernyataan berikut:

"tempatnya sempit susah mau jalan-jalan...."

"males kalau mau duduk-duduk di luar jalannya harus keliling, jauh..." (P3)

"banyak orang, takut jatuh kalo jalanjalan...." (P6)

"toiletnya jauh, jadi buang air memakai pispot saja....'(P2)

Ketersediaan alat juga dibutuhkan untuk menunjang mobilisasi, hal ini dapat dilihat pada pernyataan berikut:

"enaknya jalan-jalan keluar pakai kursi roda ya....” (P3)

"mau jalan-jalan kalau ada tongkat...." (P6)

"saya turun dari tempat tidur sambil pegangan ke kursi, tempat tidur, takut jatuh..." (P5)

"mau jalan keluar kamar kalau ada teman... takut jatuh kalau sendirian..” (P9)

\section{Keberhasilan orang lain melakukan} mobilisasi selama perawatan

Keyakinan pasien melakukan mobilisasi selama perawatan juga termotivasi oleh keberhasilan pasien lain yang mampu melakukannya. Hasil analisis dapat dilihat dari penrnyataan berikut:

"iya mau saya paksakan, pasien sebelah saya juga jalan-jalan jadi cepat sembuh......" (P5)

"saya malas, yang lain juga tiduran aja...." (P9)

"saya melihat lihat orang lain bisa jalanjalan, jadi ingin jalan-jalan juga......" (P10)

"asalnya suka lemas kalau jalan tapi saya paksakan saja, sekarang sudah bisa ke kamar mandi sendiri, ingin cepet pulang kaya bapak Dani....." (Pasien menunjuk tempat tidur sebelahnya dimana pasien lain baru saja pulang) (P5).

"alhamdulillah di kamar ini semuanya bisa ke kamar mandi sendiri, saya juga ke kamar mandi (pasien tertawa).... asalnya saya pakai pampers terus..." (P10)

\section{Pernyataan langsung dari orang lain}

Pernyataan secara verbal dari orang lain baik dari perawat, dokter, atau keluarga mempengaruhi keyakinan pasien melakukan mobilisasi. Hal tersebut dapat dilihat dari hasil analisis verbatim di bawah ini :

"suami dan saudara saya suka melarang. katanya tidak boleh turun dari tempat tidur dulu..." (P2) "tidak boleh turun dulu sama dokter dan perawat...." (P3)

"saya mau banyak bergerak, kalau diijinkan dokter.....” (P3)

"mau kalo dokter yang nyuruh....." (P9)

"Oleh dokter belum boleh turun.." (P9)

"Bapak saya suka menyuruh saya bergerak, jadi saya coba latihan jalan-jalan...” (P5)

6. Pernyataan diri pasien sendiri tentang kemampuannya melakukan mobilisasi

Pernyataan dari diri pasien sendiri tentang kemampuannya melakukan mobilisasi didapatkan dari beberapa pernyataan di bawah ini:

"iya saya sering bicara sendiri... saya bisa...saya bisa... sambil saya turun dari tempat tidur sambil pegangan ...." (PI)

"dalam hati sering bicara... harus cepat sembuh, harus kuat..." (P2)

"pokoknya saya harus kuat..." (P6)

\section{Kondisi fisik yang dirasakan pasien saat ini}

Kondisi fisik yang dirasakan saat ini dapat mempengaruhi keyakinan pasien untuk melakukan mobilisasi. Hal ini dapat dilihat pada pernyataan berikut:

"saya tidak turun tempat tidur karena ada luka....nyeri...” (P6)

"saya lemas... capek kalau jalan-jalan..." (P7)

"kalau sedang pusing saya lebih banyak tiduran saja di tempat tidur...(P1)

"lebih enak bergerak bu, tiduran terus panas punggung..."(P10)

"soalnya saya dipasang infus jadi susah jalan-jalan...” (P1)

"tidak terganggu, kalau jalan dibawa saja infusnya....” (P5)

\section{Kondisi psikis yang dirasakan pasien saat} ini

Kondisi psikis yang dirasakan pasien mempengaruhi keyakinan untuk melakukan mobilisasi. Hal ini dapat dilihat pada pernyataan berikut:

"iya semangat... ingin cepat pulang..." (P5)

"saya bisa sendiri... tidak perlu dibantu...." (P2)

"lagi males, enak tiduran saja, tidak enak keluar malu banyak orang....”(P3)

"saya kuat kok sendiri, ke kamar mandi sendiri, makan sendiri, jalan-jalan juga kuat..." (P10)

"mau sih jalan keluar kamar, tapi banyak perawat, takut mengganggu...." (P4) 


\section{PEMBAHASAN}

Karakteristik sampel penelitian menunjukkan hasil bahwa jenis kelamin sampel lebih banyak perempuan $(70 \%)$ dibanding lakilaki $(30 \%)$. Hal ini tidak mempengaruhi hasil penelitian karena beberapa penelitian menyatakan bahwa jenis kelamin tidak mempengaruhi self-efficacy (Resnick, 2002). Lama hari rawat pasien yang tergolong hari rawat pendek yaitu kurang dari satu minggu (3-6 hari) memungkinkan sampel memiliki self-efficacy yang baik seperti dinyatakan Grant \& Thesis (2000) dalam penelitiannya bahwa lebih pendek hari perawatan berhubungan dengan tingginya self-efficacy. Usia pasien yang bervariasi (22-72) menunjukkan hasil penelitian mendapatkan sumber yang bervariasi diwakili semua katagori usia dewasa dimana usia berpengaruh terhadap kekuatan otot sebagai salah satu faktor yang mempengaruhi kemampuan mobilisasi (Bautmans et al dalam Atienzar, et al 2012). Alat kesehatan yang terpasang di tubuh pasien juga bervariasi (1-3 alat) menunjukkan gambaran informasi penelitian yang didapatkan menjadi lengkap karena sampel penelitian memiliki tingkat kesulitan mobilisasi yang bervariasi.

Ke-8 tema yang dihasilkan penelitian ini dapat dijadikan acuan dalam mengkaji sumber self-efficacy mobilisasi. Tema-tema tersebut dapat diintegrasikan dengan sumber self-efficacy Bandura (1997) yang terdiri dari mastery experience, vicarious experience, verbal persuasion dan physiological and affectivestates. Mastery experience merupakan pengalaman seseorang menyelesaikan tugas tertentu dimasa lalu yang menjadi sumber terkuat kesuksesannya dalam menyelesaikan tugas-tugas saat ini (Bandura, 1997). Hasil penelitian tema ke 1-3 yaitu 1) Kebiasaan pasien melakukan mobilisasi sebelum dirawat, 2) Efek yang dirasakan pasien setelah melakukan mobilisasi, dan 3) Ketersediaan fasilitas saat pasien melakukan mobilisasi dapat diintegrasikan sebagai indikator untuk mengkaji mastery experience. Klassen (2004) dan Usher \& Pajares (2006) menyatakan bahwa mastery experienceadalah sumber paling berperan. Penelitian lain menjelaskan pentingnya mastery experience yaitu pengalaman sukses akan mendorong seseorang untuk lebih yakin akan kemampuannya (Stephen A. Templin, 2011).

Vicarious experience yaitu sumber selfefficacy berupa pemodelan sosial yang menggambarkan observasi terhadap keberhasilan orang lain yang dapat menyelesaikan tugas yang sulit dan hasil observasinya dapat meningkatkan self-efficacy individu (Bandura, 1997). Hasil penelitian tema ke-4 yaitu Keberhasilan pasien lain melakukan mobilisasi selama perawatan dapat diintegrasikan dan menjadi indikator untuk menggali Vicarious experience. Warner et al (2014) dan M. B. Harrison (2004) menyatakan seseorang yang mengamati keberhasilan orang lain memiliki self-efficacy yang lebih tinggi. Pemodelan tidak hanya dilakukan secara langsung tetapi bisa juga dilakukan secara tidak langsung misalnya dengan melihat keberhasilan orang lain melalui video (Denny, Vahidy, Vu, Sharrief, \& Savitz, 2017).

Bandura (1997) menyatakan verbal persuasion merupakan sumber self-efficacy yang menguatkan keyakinan individu yang disampaikan secara verbal bahwa dia memiliki kemampuan yang dibutuhkan untuk berhasil. Verbal persuasion dapat berupa pernyataan orang lain yang dinyatakan langsung sevara verbal ataupun pernyataan dari diri sendiri. Hasil penelitian ini tema 5 yaitu Pernyataan langsung dari orang lain kepada pasien tentang kemampuan mobilisasinya, dan tema 6 yaitu Pernyataan dari diri sendiri dapat diintegrasikan sebagai indikator dalam mengkaji verbal persuasion. Verbal persuasion menghasilkan tingkat signifikansi yang tinggi dibandingkan intervensi menggunakan sumber lainnya (Ashford, Edmunds, \& French, 2010). Penelitian lainnya menyatakan bahwa verbal persuasion efektif meningkatkan prestasi seseorang (Sangster, Lou, \& Ph, 1987).

Physiological and

merupakan sumber self-efficacy berupa persepsi seseorang terhadap perubahan kondisi fisik dan emosinya (Bandura, 1997). Hasil penelitian ini tema 7 yaitu Kondisi fisik yang dirasakan pasien saat ini, dan tema 8 yaitu Kondisi psikis yang dirasakan pasien saat ini dapat diintegrasikan menjadi indikator untuk menggali Physiological and affectivestates. Gejala fisik yang sering ditemukan pada pasien selama perawatan adalah kelemahan, nyeri, sesak nafas, pusing (Drolet et al, 2013; Demeke, Balamurugan, Alemie, \& Abebe, 2015). Sedangkan kondisi psikis yang ditemukan menghambat mobilisasi pasien adalah kurangnya motivasi dan perasaan takut (Demeke et al, 2015).

Ke-8 tema yang dihasilkan dalam penelitian ini yaitu 1) Kebiasaan pasien melakukan mobilisasi sebelum dirawat, 2) Efek yang dirasakan pasien setelah melakukan mobilisasi, 3) Ketersediaan fasilitas saat pasien melakukan mobilisasi, 4) Keberhasilan pasien lain melakukan mobilisasi selama perawatan, 5) Pernyataan langsung dari orang lain kepada pasien tentang kemampuan 
mobilisasinya, 6) Pernyataan dari diri sendiri, 7) Kondisi fisik yang dirasakan pasien saat ini, 8) Kondisi psikis yang dirasakan pasien saat ini, sesuai dan dapat diintegrasikan sebagai indikator untuk mengkaji empat sumber self-efficacy yang telah ditetapkan oleh Bandura.

\section{DAFTAR PUSTAKA}

Alibegovic, aC., Højbjerre,L., Sonne, M. P., van Hall, G., Stallknecht,B.,Dela,F.,\&Vaag, a.(2009). Impact of 9daysof bed rest on hepatic and peripheralin sulinaction, insulin secretion, and whole-body lipolysis in healthy young male off spring of patients with type 2 diabetes. Diabetes, 58(12), 2749-2756. https://doi.org/10.2337/db09-0369.

Ashford, S., Edmunds, J., \& French, D. P. (2010). What is the best way to change self-efficacy to promote lifestyle and recreational physical activity? A systematic review with meta-analysis. British Journal of Health Psychology, 15 (Pt 2), 265-288. https://doi.org/10.1348/135910709X46175 2

Atienzar, P., Abizanda, P., Guppy, a., \& Sinclair, a.J. (2012). Diabetes and frailty: an emerging issue. Part 1: Sarcopaenia and factors affecting lower limb function. TheBritish Journal of Diabetes \& Vascular Disease, 12(3), 110116. https://doi.org/10.1177/14746514124456 19

Baldwin, A. S., Rothman, A. J., Hertel, A. W., Linde, J. A., Jeffery, R. W., Finch, E. A., \& Lando, H. A. (2006). Specifying the determinants of the initiation and maintenance of behavior change: An examination of self-efficacy satisfaction, and smoking cessation. Health Psychology, 25, 626-634.

Bandura,A. (1997). Self efficacy: the exercise of control. New York: W.H. Freeman and Company.

Bandura, A. (2006). Guide for constructing selfefficacy scales. Self-Efficacy Beliefs of Adolescents, 307-337. https://doi.org/10.1017/CBO97811074153 24.004.

Cramp, A. G., \& Bray, S. R. (2009). A prospective examination of exercise and

\section{SIMPULAN}

Penelitian menyimpulkan terdapat 8 tema sumber self-efficacy mobilisasi yang dapat dijadikan indicator dalam mengkaji ke empat sumber self-efficacy yang telah ditetapkan Bandura.

barrier self- efficacy to engage in leisuretime physical activity during pregnancy. Annals of Behavioral Medicine, 37(3), 325-334. https://doi.org/10.1007/s12160009-9102-y

Demeke, S., Balamurugan, J., Alemie, G. A., \& Abebe, E. (2015). In-Hospital Mobility and Associated Factors. British Journal of Medicine and Medical Research, 5(6),780787. https://doi.org/10.9734/BJMMR/2015/1078 7

Denny, M. C., Vahidy, F., Vu, K. Y. T., Sharrief, A. Z., \& Savitz, S. I. (2017). Video-based educational intervention associated with improved stroke literacy, self- efficacy, and patient satisfaction. Plos One, 12(3), $\mathrm{e} 0171952$.

https://doi.org/10.1371/journal.pone.01719 52

Doherty-king, B., Yoon, J. Y., Pecanac, K., Brown, R., Mahoney, J., Demeke, S.,...June, U. (2012). Elderly Mobility Scale (EMS) Elderly Mobility Scale-EMS, 5 (June 2012), 780-787. https://doi.org/10.9734/BJMMR/2015/107 87

Drolet, A., DeJuilio, P., Harkless, S., Henricks, S., Kamin, E., Leddy, E. A., ... Williams, S. (2013). Move to improve: the feasibility of using an early mobility protocol to increase ambulation in the intensive and intermediate care settings. Physical Therapy, 93(2), 197-207. https://doi.org/10.2522/ptj.20110400

Fuerst, E.V., \& Wolff, L. (Eds.). (1969). Providing for posture and exercise needs. In Fundamentals in nursing (pp. 204-239). Philadelphia, PA: J.B. Lippincott.

Grant, \& Thesis, C. (2000). Information to users. Arbor Ciencia Pensamiento $Y$ Cultura, 6 . https://doi.org/10.16953/deusbed.74839 
Harrison, A.L. (2004). The Influence of Pathology, Pain, Balance, and Selfefficacyon. Physical Therapy, 84(9).

Harrison, M. B. (2004). An Investigation Of The Influence of Vicarious Experience On Perceived Self-Efficacy. Clemson University.

Hellström, K., Lindmark, B., Wahlberg, B., \& Fugl-Meyer, A.R. (2003). Self-efficacy in relation to impairments and activities of daily living disability in elderly patients with stroke: A prospective investigation. Journal of Rehabilitation Medicine, 35(5), 202-207. https://doi.org/10.1080/1650197031000083 6.

Klassen, R. M. (2004). A cross-cultural investigation of the efficacy beliefs of South Asian immigrant and Anglo Canadian nonimmigrant early adolescents. Journal of Educational Psychology, 96, 731-742.

Kleffelgaard, I., Roe, C., Sandvik, L., Hellstrom, T., \& Soberg, H. L. (2013). Measurement properties of the high-level mobility assessment tool for mild traumatic brain injury. Physical therapy, 93(7), 900-910.

Krasnoff, J., \& Painter, P. (1999). The physiological consequences of bed rest and inactivity. Advances in Renal Replacement Therapy, 6(2), 124-132.

Liu,Q., Zhou, R., Chen, S., \& Tan, C. (2012). Effects of Head-Down Bed Rest on the Executive Functions and Emotional Response. PLoSONE, 7(12). https://doi.org/10.1371/journal.pone.0052 160

Oei, T. P. S., \& Burrow, T. (2000). Alcohol expectancy and drinking refusal selfefficacy: A test of specificity theory. Addictive Behaviors, 25, 499-507.

Perry\&Potter. (2006). Fundamental of Nursing: Concept, Process, and Practice. Mosby, Inc.

Resnick, B. (2002). Geriatric rehabilitation: the influence of efficacy beliefs and motivation. Rehabilitation Nursing: The Official Journal of the Association of Rehabilitation Nurses, 27 (4), 152-159. https://doi.org/10.1002/j.20487940.2002.tb02224.x

Roberts, B.L., Dolansky, M.a., \& Weber, B.a. (2010). Psychometric Properties of the Task
Self-Efficacy Scale for Everyday Activities in Older Adults. Research and Theory for Nursing Practice, 24(2),113-127. https://doi.org/10.1891/15416577.24.2.113.

Sangster, L. R. (1987). Self-efficacy: the effects of verbal persuasion and goal setting on performance outcomes (Doctoral dissertation, School of Education. University of Missouri-Kansas City).

Sonne, M.P., Alibegovic, A.C., Højbjerre, L., Vaag,A, Stallknecht, B., \& Dela, F. (2010). Effect of 10 days of bedrest on metabolic and vascular insulin action: a studying individuals at risk for type 2 diabetes. Journal of Applied Physiology (Bethesda, Md.:1985), 108 (4), 830-837. https://doi.org/10.1152/japplphysiol.00545 2009 .

Smorawiński, J., Nazar, K., Kaciuba-Uscilko, H., Kamińska,E., Cybulski, G.,Kodrzycka, a,...Greenleaf, J.E. (2001). Effects of 3daybed reston physiological responses to graded exercise in athletes and sedentary men. Journal of Applied Physiology (Bethesda,Md.:1985), 91(1), 249-257.

Stephen A. Templin. (2011). Examining the Effects of Self-Efficacy Sources on English as a Second Language (ESL) SelfEfficacy Beliefs and ESL Proficiency A Dissertation of Trident University International In Partial Fulfillment of the Requirements for the Degree of Doctor of Phil. Unpublished Dissertation.

Theresa, M., \& Fox, C. (2007). Reproduced with permission of the copyright owner. Further reproduction prohibited without permission.

Usher, E. L., \& Pajares, F. (2006). Sources ofacademic and self-regulatory efficacy beliefs of entering middle school students. Contemporary Educational Psychology, 31, 125-141. doi:10.1016/j.cedpsych.2005.03.002

Warner, L. M., Schüz, B., Wolff, J.K., Parschau, L., Wurm,S., \& Schwarzer, R. (2014). Sources of Self-Efficacy for Physical Activity. Health Psychology, 33 (11), 1298-1308.

https://doi.org/http://dx.doi.org/10.1037/h ea0000085 